\title{
PRODUÇÃO DE SEMENTES DE SOJA SOBRE SOLO DE VÁRZEA ALAGADA
}

\author{
Marcos Paulo Ludwig ${ }^{1}$, Sandro Oliveira ${ }^{2}$, Luiz Osmar Braga Schuch ${ }^{2}$, Francisco Jesus Vernetti \\ Junior $^{3}$, Rogério Seus ${ }^{2}$, Marciabela Fernandes Corrêa ${ }^{2}$, Thiago Lima Nunes ${ }^{2}$ \\ ${ }^{1}$ Instituto Federal do Rio Grande do Sul, e-mail: marcos.ludwig@ibiruba.ifrs.edu.br \\ ${ }^{2}$ Universidade Federal de Pelotas, e-mail: sandrofaem@yahoo.com.br, lobs@ufpel.edu.br, rseus@ibest.com.br, \\ marciabelafc@yahoo.com.br, thiagolnunes14@gmail.com \\ ${ }^{3}$ Embrapa Clima Temperado, e-mail: francisco.vernetti@embrapa.br
}

\section{RESUMO}

O objetivo deste trabalho foi avaliar o efeito do alagamento do solo de várzea, em diferentes estádios fenológicos da cultura da soja, na qualidade das sementes. A qualidade fisiológica de sementes é afetada negativamente pelo alagamento do solo, impedindo a produção de sementes com qualidade. Há relação entre o peso de 1000 sementes e a distribuição das sementes em peneiras, porém não há relação com a qualidade fisiológica das sementes. $\mathrm{O}$ alagamento altera a distribuição das sementes em peneiras classificadoras, com maior retenção em peneiras de maior diâmetro.

Palavras-chave: Sementes, Glycine max, produtividade, tolerância ao alagamento

\section{PRODUCTION OF SOYBEAN SEEDS ON FLOODED LOWLAND}

\begin{abstract}
This paper evaluates the effect of flooding lowland, in different growing stages of soybean crop on seed quality. The seed physiological quality is adversely affected by flooding, preventing the production of good quality seeds. There is a relationship between the weight of 1000 seeds and seed distribution in sieves, but not to seed quality. Flooding alters the distribution of the seeds in classification sieves, with a higher retention in larger diameter sieves.
\end{abstract}

Keywords: Seeds, Glycine max, yield, tolerance to flooding

\section{INTRODUÇÃO}

É crescente o uso da cultura da soja em locais com possibilidade de alagamento do solo, fato este que está relacionado à grande área com solos aluviais e hidromórficos. No Brasil, estima-se que haja cerca de 28 milhões de hectares de solos sujeitos ao alagamento (MAGALHÃES et 
al., 2005). Além disso, a cultura da soja é uma das alternativas importantes dentro do sistema produtivo do arroz irrigado, permitindo a realização de rotação de cultura.

Um dos fatores que dificultam o cultivo da soja é o excesso de precipitação hídrica em determinadas épocas de cultivo, resultando em períodos de alagamento do solo. Como efeitos do alagamento pode-se citar a redução da área foliar (ZENZEN et al., 2007), redução da capacidade de fotossíntese (SERRES \& VOESENEK, 2008), redução da concentração de nitrogênio no tecido foliar (SULLIVAN et al., 2001) e redução dos pigmentos clorofila a e b em plantas de soja submetidas à inundação do solo (AMARANTE et al., 2007). São afetadas outras características da morfologia como redução na altura de plantas (CHO \& YAMAKAWA, 2006) e formação de aerênquima (DREW et al., 2000). Considerando a soja uma espécie que pode responder a esta condição de alagamento do solo e pela diversidade genética presente na cultura, as respostas das plantas à inundação podem ser diversas. Podem ser incluídas ainda alterações na arquitetura, no metabolismo e no alongamento do crescimento (SERRES \& VOESENEK, 2008).
O objetivo deste trabalho foi avaliar o efeito do alagamento do solo, em diferentes estádios fenológicos da cultura da soja, sobre a qualidade das sementes.

\section{MATERIAL E MÉTODOS}

Os experimentos foram conduzidos na Estação Experimental de Terras Baixas, da Embrapa Clima Temperado, localizada no Município de Capão do Leão, RS (31 ${ }^{\circ} 52^{\prime} 00$ '’S, 52²1'24',W), em um Planossolo Háplico Eutrófico Solódico com textura franco-arenosa, de profundidade entre 20 e $40 \mathrm{~cm}$ e horizonte B impermeável, durante as safras 2008/2009 e 2009/2010. Os testes para avaliar a qualidade fisiológica das sementes foram realizados no Laboratório Didático de Análise de Sementes da Faculdade de Agronomia Eliseu Maciel, da Universidade Federal de Pelotas.

No primeiro ano de cultivo foram utilizados os genótipos: BRS 243 RR, CD 213 RR, CD 221, IAS 5, BRS 244 RR, BRS 246 RR, BRS Fepagro 24, BRS Taura RR, BRS Cambona e CLBRS 9911. No segundo ano foram utilizados os genótipos BMX Apolo, BRS 244 RR, BRS 246 RR, BRS Fepagro 24, BRS Macota, BRS Taura RR, CD 213 RR, CD 221, Fundacep 53 RR e IAS 5. 
Nos dois anos foram aplicados três sistemas de manejo da água nas plantas: condição normal de cultivo (sem alagamento, SA); alagamento no período vegetativo, quando as plantas encontravamse no estádio V3/V4 (visando verificar os efeitos do alagamento no período vegetativo, APV); alagamento no período reprodutivo, quando as plantas encontravam-se no estádio R2/R3 (visando verificar os efeitos do alagamento no período reprodutivo, APR). Utilizou-se a escala de Fehr \& Caviness (1977) para definição dos estádios fenológicos.

Os períodos de alagamento no primeiro ano foram de 22 a 29 de dezembro de 2008 e de 5 a 12 de fevereiro de 2009, respectivamente para V3/V4 e R2/R3. No segundo ano de cultivo os períodos de alagamento ocorreram de 6 a 14 de janeiro de 2010, para V3/V4 e de 13 a 18 de fevereiro de 2010, para R2/R3.

$\mathrm{Na}$ safra 2008/2009, as parcelas permaneceram sob alagamento por sete dias consecutivos em ambos os períodos (vegetativo e reprodutivo), enquanto na safra 2009/2010, as parcelas permaneceram por oito dias no período vegetativo e cinco no período reprodutivo.
Nas parcelas que receberam alagamento foram construídas taipas ao redor das mesmas para possibilitar a manutenção de uma lâmina de água de cinco centímetros de altura, que foi mantida pelos períodos descritos. Logo após, a área foi drenada e as parcelas permaneceram sob condições naturais de cultivo até a maturação.

O delineamento experimental utilizado foi blocos casualizados com parcelas subdivididas, com quatro repetições. Nas parcelas principais foram dispostos os manejos de água e nas subparcelas os genótipos. Os genótipos foram agrupados conforme o ciclo de maturação para homogeneizar o momento de entrada de água na área principalmente no período reprodutivo. As subparcelas foram compostas de quatro linhas de cinco metros de comprimento, espaçadas em $0,50 \mathrm{~m}$; a área útil foi constituída das duas linhas centrais, eliminando-se $0,50 \mathrm{~m}$ de cada extremidade, perfazendo o total de $4,0 \mathrm{~m}^{2}$. A densidade de semeadura utilizada foi estipulada para obtenção de uma população de plantas inicial de 300 mil plantas por hectare. Na safra 2008/2009 a semeadura foi realizada dia 19 de novembro de 2008, enquanto na safra 2009/2010 foi dia 10 de dezembro de 2009. Em ambos os anos a 
adubação utilizada foi de $350 \mathrm{~kg} \mathrm{ha}^{-1}$ do adubo da fórmula 52010 .

\section{Qualidade fisiológica das sementes}

Foram realizados testes de germinação, vigor (primeira contagem, envelhecimento acelerado), já para a qualidade física foram realizados os testes de peso de 1000 sementes e de distribuição das sementes em peneiras classificadoras.

\section{Teste de germinação}

Utilizaram-se 200 sementes por tratamento, divididas em quatro subamostras de 50 sementes, em rolo de papel germitest umedecido com água. Exceto pelo número de sementes, mantiveram-se as recomendações das Regras para Análise de Sementes - RAS (BRASIL, 2009). Os rolos foram levados ao germinador à temperatura de $25^{\circ} \mathrm{C}$ por oito dias, quando foi realizada a avaliação final. Os resultados foram expressos em porcentagem de plântulas normais.

\section{Testes de vigor}

Primeira contagem da germinação: realizado conjuntamente ao teste de germinação, sendo a contagem das plântulas normais executada aos cinco dias após início do teste (BRASIL, 2009). Os resultados foram expressos em porcentagem de plântulas normais.

\section{Envelhecimento acelerado}

Foram analisadas 200 sementes, as quais foram divididas em quatro subamostras de 50 sementes, utilizando-se o método de gerbox adaptado. As sementes foram espalhadas em camada única sobre uma tela suspensa dentro de caixas de gerbox, contendo $40 \mathrm{~mL}$ de água destilada. Posteriormente essas caixas permaneceram em câmara BOD por $48 \mathrm{~h}$, a $41^{\circ} \mathrm{C}$ (MARCOS FILHO, 2005). Após este período as sementes foram colocadas para germinar conforme metodologia descrita para o teste de germinação (BRASIL, 2009). Os resultados foram expressos em porcentagem de plântulas normais aos cinco dias após início do teste.

Para a determinação do peso de 1000 sementes foram tomadas oito repetições contendo cada uma 100 sementes e pesadas em balança analítica; posteriormente, todas as amostras foram ajustadas para o teor de água de $13 \%$, determinando-se o peso de 1000 sementes, de acordo com o indicado nas RAS (BRASIL, 2009).

Para a determinação da distribuição das sementes em peneiras classificadoras foram tomadas duas amostras de $200 \mathrm{~g}$ em cada parcela, as quais foram colocadas em uma sequência de peneiras de furos 
redondos, superpostas em ordem decrescente de diâmetro, avaliando-se a porcentagem de retenção de sementes em cada peneira (MARCOS FILHO et al., 2000).

Para a análise estatística, os dados em porcentagem foram transformados para arcoseno $\sqrt{(x \backslash 100)}$ e posteriormente foi realizada análise da variância e teste de hipóteses para verificar a significância dos efeitos principais e das interações. A comparação de médias foi realizada pelo teste de Tukey, a 5\% de probabilidade.

\section{RESULTADOS E DISCUSSÃO}

Para a qualidade fisiológica de sementes que foi avaliada pelos testes de germinação (Tabela 1), primeira contagem de germinação e de envelhecimento acelerado (Tabela 2) pode-se constatar que o alagamento do solo, de maneira geral, causa efeito negativo na qualidade fisiológica das sementes, sobretudo nos dados do segundo ano de condução do trabalho. Também foi constatada interação entre genótipos e manejo de água. No primeiro ano, não foi verificada diferença entre genótipos no teste de germinação em condição de cultivo sem alagamento. No entanto, quando há alagamento tanto no período vegetativo como no período reprodutivo, ocorrem diferenças de germinação entre genótipos, devido aos efeitos do alagamento sobre a qualidade fisiológica das sementes.

Os genótipos BRS 244 RR, BRS Taura RR, CLBRS 9911 e IAS 5 apresentaram diferenças entre os manejos de alagamento, sendo os menores valores de germinação obtidos quando este ocorreu no período vegetativo. Já no segundo ano de cultivo (Tabela 1), houve maiores evidências do efeito negativo ocasionado pelo alagamento do solo sobre a germinação, pois somente o genótipo Fundacep 53 RR, não apresentou redução na germinação. O alagamento no período vegetativo também não afetou a germinação do genótipo BMX Apolo da mesma maneira como durante o período reprodutivo, também se observou efeito na germinação dos genótipos BRS 246 RR e BRS Taura RR, além da Fundacep 53RR.

A análise de variância, realizada dentro de cada época de manejo, no primeiro ano de cultivo, os genótipos BRS 243 RR, BRS 246 RR, BRS FEPAGRO 24, CD 213 RR, CD 221 e CLBRS 9911 tiveram suas sementes com germinação igual ou superior a $80 \%$, em ambas as condições de cultivo. Por outro lado, as sementes produzidas em condição de alagamento no período vegetativo os genótipos BRS 244 RR, BRS Cambona, BRS Taura RR e IAS 5 tiveram 
germinação inferior a $80 \%$ e não seriam aprovadas para fins de comercialização. Ainda no primeiro ano, quando $\mathrm{O}$ alagamento foi realizado em R2/R3, apenas o genótipo BRS Cambona não seria aprovado para comercialização.

No segundo ano de experimento destacaram-se os genótipos BMX Apolo, BRS Macota e Fundacep 53 RR com germinação acima de $80 \%$ em todas as condições de cultivo. No entanto com alagamento em V3/V4 foi observado que os genótipos BRS 246 RR, BRS Fepagro 24, BRS Taura RR, CD 221 e IAS 5 não tiveram germinação acima de $80 \%$ e não seriam aprovados para fins de comercialização. No alagamento em R2/R3, apenas BMX Apolo, BRS 246 RR, BRS Macota e Fundacep 53 RR teriam germinação acima do nível mínimo para comercialização. No entanto, na condição sem alagamento todos os genótipos seriam aprovados para comercialização, com germinação acima de $80 \%$. Assim, pode-se afirmar que quando não ocorre alagamento no solo é possível produzir semente de soja com germinação mínima para aprovação pela legislação, em solo de várzea. Porém com alagamento há problemas com a qualidade fisiológica das sementes, mesmo havendo genótipo com germinação acima de $80 \%$ em ambas as condições de cultivo, isso não ocorreu nos dois anos de cultivo. Resultado constatado na repetição do cultivo dos genótipos, BRS 246 RR, BRS Fepagro 24, CD 213 RR, CD 221 , os quais tiveram bom desempenho no primeiro ano (germinação acima de $80 \%$ em todas as condições de cultivo), mas não no segundo ano.

No primeiro ano de cultivo, a primeira contagem da germinação (Tabela 2) também não apresentou diferença entre genótipos sob condição sem alagamento. No entanto, assim como para a germinação, os genótipos apresentaram comportamento diferenciado quando o alagamento ocorreu nas diferentes épocas. Os genótipos BRS 244 RR, BRS Taura RR e IAS 5 apresentaram os menores valores para a primeira contagem da germinação quando ocorreu alagamento no período vegetativo. Já o genótipo BRS Cambona apresentou menor valor de primeira contagem da germinação quando o alagamento ocorreu no período reprodutivo. Os demais genótipos não foram afetados pelo alagamento do solo. A primeira contagem da germinação no segundo ano mostrou diferença entre genótipos em todos os manejos. Quando ocorreu o alagamento, todas os genótipos responderam negativamente em ambos ou em algum dos períodos. Assim como na 
germinação, os genótipos BRS Fepagro 24 e BRS Taura RR apresentaram os menores valores de primeira contagem da germinação no manejo sem alagamento. Destaca-se novamente o efeito negativo do alagamento do solo, agora no vigor, da mesma como constatado na germinação não se observou genótipos tolerantes a esta condição no trabalho.

Para o teste de envelhecimento acelerado no primeiro ano de cultivo, no tratamento sem alagamento, foi constatado que os genótipos BRS 243 RR e IAS 5 foram os que apresentaram o maior e o menor valor, respectivamente 87 e $72 \%$. Para o alagamento no período vegetativo, o genótipo IAS 5 apresentou vigor inferior aos genótipos BRS 243 RR e CLBRS 9911, enquanto que quando o alagamento foi no período reprodutivo o genótipo CLBRS 9911 apresentou comportamento superior aos genótipos BRS 244 RR, BRS Cambona, BRS Fepagro 24, CD 213 RR, CD 221 e IAS 5. De forma geral, o alagamento ocorrido, tanto no período vegetativo como no período reprodutivo, não afetou o vigor das sementes, comparativamente ao tratamento sem alagamento, com exceção do genótipo CD 213 RR, que sofreu redução no vigor. O genótipo CLBRS 9911 apresentou maior porcentagem de plântulas normais no teste de envelhecimento acelerado nas sementes obtidas da área que foi mantida sob alagamento em período reprodutivo. Novamente no segundo ano, assim como os resultados da primeira contagem da germinação, os resultados do teste de envelhecimento acelerado mostraram redução da qualidade fisiológica das sementes produzidas sob condição de alagamento do solo. Sem alagamento, o genótipo BRS Taura RR apresentou o menor valor. Quando ocorreu alagamento no período vegetativo, os menores valores de plântulas normais foram obtidos nos genótipos BRS Taura RR, CD 221 e IAS 5. Ao se proceder a avaliação nas sementes produzidas com alagamento em R2/R3, os menores valores de plântulas normais neste teste foram obtidos nos genótipos BRS 244 RR, BRS Fepagro 24, CD 221 e IAS 5.

Os resultados da germinação e primeira contagem da germinação podem indicar a existência de genótipos mais sensíveis ao alagamento do solo, pois os resultados mostraram que em ambos os anos de cultivos os genótipos IAS 5 e BRS Taura RR apresentaram os menores valores de germinação e primeira contagem em alagamento ocorrido no período vegetativo. 
Tabela 1. Germinação de sementes de soja (\%) e peso de 1000 sementes (g), em dois anos (2008/2009 - Ano 1; 2009/2010 - Ano 2) submetidas a três manejos de alagamento do solo [sem (SA); com alagamento no período vegetativo (APV); e no período reprodutivo (APR)]. Embrapa Clima Temperado, Capão do Leão-RS, Brasil, 2013.

\begin{tabular}{|c|c|c|c|c|c|c|}
\hline \multicolumn{7}{|c|}{ Ano 1} \\
\hline & \multicolumn{3}{|c|}{ Germinação } & \multicolumn{3}{|c|}{ Peso de 1000 sementes } \\
\hline Genótipo & SA & APV & APR & SA & APV & APR \\
\hline BRS 243 RR & 90 a A & 86 a A & 91 a A & 128 e $^{1}$ & $127 \mathrm{f} \mathrm{A}$ & $114 \mathrm{fB}$ \\
\hline BRS 244 RR & 85 a $\mathrm{A}$ & $74 \mathrm{abc} B$ & $85 \mathrm{ab} A$ & 132 de $\mathrm{C}$ & $144 \mathrm{dcb} B$ & $153 \mathrm{dcb} A$ \\
\hline BRS 246 RR & 82 a A & 85 a $\mathrm{A}$ & $84 \mathrm{ab} A$ & 135 de $\mathrm{B}$ & $134 \mathrm{fe} \mathrm{B}$ & $145 \mathrm{~d} \mathrm{~A}$ \\
\hline BRS Cambona & 83 a A & 78 abc A & $75 \mathrm{~b} \mathrm{~A}$ & $141 \mathrm{~d} \mathrm{~B}$ & 134 fed B & $155 \mathrm{cb} \mathrm{A}$ \\
\hline BRS Fepagro 24 & 83 a $\mathrm{A}$ & $82 \mathrm{abc} A$ & $83 \mathrm{ab} A$ & $156 \mathrm{c} \mathrm{A}$ & 142 edcb B & $157 \mathrm{c} \mathrm{A}$ \\
\hline BRS Taura RR & $81 \mathrm{a} \mathrm{AB}$ & $72 \mathrm{bc} \mathrm{B}$ & $83 \mathrm{ab} \mathrm{A}$ & $164 \mathrm{cb} \mathrm{B}$ & $149 \mathrm{cb} \mathrm{C}$ & 172 a A \\
\hline CD 213 RR & 89 a A & $83 \mathrm{abc} A$ & $81 \mathrm{ab} A$ & 133 de A & 140 edc A & $122 \mathrm{fB}$ \\
\hline CD 221 & 88 a A & 84 a $\mathrm{A}$ & $87 \mathrm{ab} A$ & $168 \mathrm{ab} A$ & $151 \mathrm{~b} \mathrm{~B}$ & $146 \mathrm{dc} B$ \\
\hline CLBRS 9911 & 87 a A & 84 a B & 92 a A & 33 de $\mathrm{AB}$ & 139 edc $A$ & 132 e B \\
\hline IAS 5 & 85 a B & $71 \mathrm{c} \mathrm{C}$ & 91 a A & 175 a A & 167 a B & $158 \mathrm{~b} \mathrm{C}$ \\
\hline Média & 85 & 80 & 85 & 146 & 143 & 145 \\
\hline $\mathrm{F}$ & \multicolumn{3}{|c|}{$*$} & \multicolumn{3}{|c|}{$*$} \\
\hline CV. $(\%)$ & \multicolumn{3}{|c|}{2,7} & \multicolumn{3}{|c|}{2,5} \\
\hline \multicolumn{7}{|c|}{ Ano 2} \\
\hline & \multicolumn{3}{|c|}{ Germinação } & \multicolumn{3}{|c|}{ Peso de 1000 sementes } \\
\hline BMX Apolo & $94 \mathrm{ab} \mathrm{A}$ & 93 a $\mathrm{A}$ & $81 \mathrm{ab} \mathrm{B}$ & $147 \mathrm{bc} \mathrm{B}$ & 147 de B & $165 \mathrm{bc} \mathrm{A}$ \\
\hline BRS 244 RR & $92 \mathrm{ab} \mathrm{A}$ & 80 bcde $\mathrm{B}$ & 75 bc B & 142 c B & $161 \mathrm{~cd} \mathrm{~A}$ & $154 \mathrm{c} \mathrm{A}$ \\
\hline BRS 246 RR & $92 \mathrm{ab} A$ & 78 cde B & 86 a A & $126 \mathrm{~d} \mathrm{~A}$ & 136 ef $A$ & $134 \mathrm{~d} \mathrm{~A}$ \\
\hline BRS Fepagro 24 & $85 \mathrm{bc} \mathrm{A}$ & 73 de B & $63 \mathrm{~d} \mathrm{C}$ & 163 a B & 163 bc B & 181 a $\mathrm{A}$ \\
\hline BRS Macota & 97 a A & $89 \mathrm{abc} A B$ & 87 a B & $138 \mathrm{~cd} \mathrm{~B}$ & 140 ef B & $154 \mathrm{c} \mathrm{A}$ \\
\hline BRS Taura RR & $80 \mathrm{c} \mathrm{A}$ & 70 e $\mathrm{B}$ & $75 \mathrm{bc} A B$ & $156 \mathrm{ab} B$ & $174 \mathrm{ab} A$ & $175 \mathrm{ab} A$ \\
\hline CD 213 RR & $94 \mathrm{ab} A$ & 83 abcd B & $74 \mathrm{bc} \mathrm{C}$ & $126 \mathrm{~d} \mathrm{~B}$ & $131 \mathrm{f} \mathrm{AB}$ & $136 \mathrm{~d} \mathrm{~A}$ \\
\hline CD 221 & $93 \mathrm{ab} A$ & $58 \mathrm{fC}$ & 74 bc B & $151 \mathrm{abc} A$ & $160 \mathrm{~cd} \mathrm{~A}$ & 159 c A \\
\hline Fundacep 53 RR & $95 \mathrm{ab} A$ & $89 \mathrm{ab} A$ & 88 a A & $144 \mathrm{bc} \mathrm{B}$ & $160 \mathrm{~cd} \mathrm{~A}$ & $152 \mathrm{c} \mathrm{AB}$ \\
\hline IAS 5 & 96 a A & $58 \mathrm{fC}$ & $71 \mathrm{~cd} \mathrm{~B}$ & 149 bc C & 177 a A & 162 bc B \\
\hline Média & 92 & 77 & 78 & 144 & 155 & 157 \\
\hline $\mathrm{F}$ & \multicolumn{3}{|c|}{$*$} & \multicolumn{3}{|c|}{$*$} \\
\hline CV. $(\%)$ & \multicolumn{3}{|c|}{2,3} & \multicolumn{3}{|c|}{3,3} \\
\hline
\end{tabular}

+ Médias seguidas por mesma letra minúscula na coluna e maiúscula na linha não diferiram pelo teste de Tukey a $5 \%$ de probabilidade; * teste $\mathrm{F}$ significativo a 5\% para a interação genótipo $\mathrm{x}$ tratamento de alagamento; ns - teste $\mathrm{F}$ não significativo. 
Nesta condição, o genótipo IAS 5 também apresentou o menor valor no teste de envelhecimento acelerado.

$\mathrm{O}$ alagamento no período reprodutivo proporcionou menores valores de germinação e primeira contagem para o genótipo BRS Cambona no primeiro ano de cultivo. No segundo ano, os genótipos IAS 5 e BRS Fepagro 24 apresentaram os menores valores de germinação e primeira contagem da germinação com alagamento no período reprodutivo. Para a primeira contagem, neste ano além desse genótipo o BRS 244 RR apresentou valores baixos.

Alterações na qualidade fisiológica das sementes estão relacionadas a fatores que abrangem, entre outras condições, períodos de seca, danos por insetos, extremos de temperatura durante a maturação e fortes flutuações das condições de umidade do ambiente (FRANÇA-NETO et al., 2000). Trabalhos com Arabidopsis mostram que a partir de 0,5 horas sob baixa concentração de oxigênio as plantas começam a alterar o conjunto de genes expressos (KLOK et al., 2002), no tocante à qualidade fisiológica das sementes tal efeito pode alterar o desempenho das sementes produzidas sob esta condição. Loreti et al. (2005) observaram alteração no processo de síntese de sacarose com a permanência das plantas sob anoxia, o que altera o crescimento das plântulas de Arabidopsis, pois, aparentemente, a sacarose é o açúcar de transporte que levará os produtos da mobilização da reserva até o embrião em crescimento (BUCKERIDGE et al., 2000).

Durante o processo de formação das sementes de soja, Hajduchet al. (2005) identificaram 422 proteínas que estão envolvidas com o metabolismo de outras proteínas, armazenamento, transporte de metabólitos e mecanismos de defesa da planta. Possivelmente, o estresse ocasionado pelo alagamento pode alterar o metabolismo da planta afetando a síntese destas proteínas e assim alterar a qualidade fisiológica das sementes produzidas.

Quanto à qualidade física, o peso de 1000 sementes, foi influenciado pela interação entre os fatores genótipos e manejo de alagamento, em ambos os anos de avaliação (Tabela 1). No primeiro ano, foram observadas diferenças entre os tratamentos de manejo de alagamento do solo em todos os genótipos. No segundo ano, não se observou diferença entre tratamentos de manejo de alagamento para os genótipos BRS 246 RR e CD 221. No primeiro ano, o alagamento no período vegetativo provocou redução no peso de 1000 sementes nos 
genótipos BRS Fepagro 24, BRS Taura RR, CD 221 e IAS 5.

$\mathrm{O}$ alagamento durante $\mathrm{o}$ período reprodutivo reduziu o peso de 1000 sementes nos genótipos BRS 243 RR, CD 213 RR, CD 221 e IAS 5. Na safra 2008/2009 o alagamento durante o período vegetativo não provocou aumento no peso de 1000 sementes em nenhum genótipo. No entanto, $\mathrm{o}$ alagamento aplicado durante o período reprodutivo aumentou o peso de 1000 sementes nos genótipos BRS 244 RR, BRS 246 RR, BRS Cambona e BRS Taura RR.

No segundo ano de avaliação nenhum dos tratamentos reduziu o peso de 1000 sementes. O alagamento no período vegetativo aumentou o peso das sementes dos genótipos BRS 246 RR, BRS Taura RR, CD 221, Fundacep 53 RR e IAS 5. Os resultados observados nos genótipos BRS Taura RR e IAS 5 divergem dos observados durante o primeiro ano. $\mathrm{O}$ alagamento no período reprodutivo aumentou o peso de 1000 sementes nos genótipos BMX Apolo, BRS 244 RR, BRS Fepagro 24, BRS Macota, BRS Taura RR, CD 213 RR e IAS 5 , resultados diferentes dos observados nos genótipos CD 213 RR e IAS 5, no primeiro ano. $\mathrm{O}$ fato de o alagamento resultar em sementes mais pesadas, tem relação com o que foi explicado por Kuss et al. (2008), que relacionam o maior peso de sementes em condição de estresse, com o maior porcentual de abortamento de flores e legumes. Assim sendo, os legumes que permanecem na planta acumulam maior quantidade de matéria seca nas sementes desenvolvidas, do que, comparativamente, os das plantas com maior número de legumes cheios com sementes, onde é maior a demanda por fotoassimilados. Casagrande et al. (2001) explicam este comportamento como sendo um mecanismo de tolerância a déficit hídrico, com o objetivo de direcionar o fluxo de fotoassimilados para os legumes que se apresentam mais adiantados no processo de desenvolvimento e que, em teoria, teriam maiores chances de produzir sementes viáveis.

Alteração no peso de sementes também foi observado por Rambo et al. (2003), os quais registraram aumento no peso das sementes quando as plantas se apresentavam mais equidistantes. Como é uma situação de estresse, possivelmente tenha ocorrido mortalidade de plantas, ocasionada pelo alagamento, assim contribuindo para o aumento do peso de sementes. Fato que pode ser constatado é que não há relação entre as respostas do peso de 1000 sementes com qualidade fisiológica, pois os comportamentos são muito variáveis. 
Tabela 2. Primeira contagem da germinação e envelhecimento acelerado de sementes de soja (\%), em dois anos (2008/2009 - Ano 1; 2009/2010 - Ano 2), submetidas a três manejos de alagamento do solo [sem (SA); com alagamento no período vegetativo (APV); e no período reprodutivo (APR)]. Embrapa Clima Temperado, Capão do Leão-RS. Brasil, 2013.

\begin{tabular}{|c|c|c|c|c|c|c|}
\hline \multicolumn{7}{|c|}{ Ano 1} \\
\hline & \multicolumn{3}{|c|}{ Primeira Contagem } & \multicolumn{3}{|c|}{ Envelhecimento Acelerado } \\
\hline Genótipo & SA & APV & APR & SA & APV & APR \\
\hline BRS 243 RR & 87 a A & 84 a A & 87 a A & 86 a A & 78 a A & $78 \mathrm{ab} \mathrm{A}$ \\
\hline BRS 244 RR & 83 a A & 72 abc B & 82 abc $A$ & $79 \mathrm{ab} A$ & $71 \mathrm{ab} A$ & 77 b A \\
\hline BRS 246 RR & 79 a A & 81 a A & 80 abc $\mathrm{A}$ & $77 \mathrm{ab} A$ & $77 \mathrm{ab} A$ & $80 \mathrm{ab} A$ \\
\hline BRS Cambona & 79 a A & 75 abc $A$ & $72 \mathrm{c} \mathrm{A}$ & $75 \mathrm{ab} A$ & $74 \mathrm{ab} A$ & $70 \mathrm{~b} \mathrm{~A}$ \\
\hline BRS Fepagro 24 & 80 a A & $79 \mathrm{ab} A$ & 80 abc $\mathrm{A}$ & $77 \mathrm{ab} A$ & $73 \mathrm{ab} A$ & $74 \mathrm{~b} \mathrm{~A}$ \\
\hline BRS Taura RR & 78 a $\mathrm{AB}$ & $70 \mathrm{bc} \mathrm{B}$ & 79 abc A & $77 \mathrm{ab} A$ & $71 \mathrm{ab} A$ & $78 \mathrm{ab} \mathrm{A}$ \\
\hline CD 213 RR & 85 a A & 77 abc AB & 74 bc B & $82 \mathrm{ab} A$ & $73 \mathrm{ab} \mathrm{B}$ & $70 \mathrm{~b} \mathrm{~B}$ \\
\hline CD 221 & 84 a A & 81 a A & $85 \mathrm{ab} A$ & $79 \mathrm{ab} A$ & $76 \mathrm{ab} A$ & $76 \mathrm{~b} \mathrm{~A}$ \\
\hline CLBRS 9911 & 83 a $\mathrm{A}$ & 81 a $\mathrm{A}$ & $85 \mathrm{ab} A$ & $80 \mathrm{ab} B$ & 79 a B & 88 a $\mathrm{A}$ \\
\hline IAS 5 & 80 a A & 65 c B & 83 abc A & $72 \mathrm{~b} \mathrm{~A}$ & $66 \mathrm{~b} \mathrm{~A}$ & 72 b A \\
\hline Média & 82 & 76 & 81 & 78 & 74 & 76 \\
\hline $\mathrm{F}$ & \multicolumn{3}{|c|}{$*$} & \multicolumn{3}{|c|}{$*$} \\
\hline CV. $(\%)$ & \multicolumn{3}{|c|}{2,8} & \multicolumn{3}{|c|}{2,6} \\
\hline \multicolumn{7}{|c|}{ Ano 2} \\
\hline & \multicolumn{3}{|c|}{ Primeira Contagem } & \multicolumn{3}{|c|}{ Envelhecimento Acelerado } \\
\hline BMX Apolo & 89 a $\mathrm{A}$ & 90 a A & $76 \mathrm{ab} B$ & 89 a A & 77 a B & 66 a B \\
\hline BRS 244 RR & $85 \mathrm{ab} A$ & $73 \mathrm{bcd} B$ & $64 \mathrm{c} \mathrm{C}$ & 85 a $\mathrm{A}$ & $67 \mathrm{abc} B$ & $50 \mathrm{bcd} C$ \\
\hline BRS 246 RR & $84 \mathrm{ab} A$ & 72 cde $B$ & $81 \mathrm{a} \mathrm{A}$ & 84 a A & $60 \mathrm{bc} \mathrm{C}$ & 72 a B \\
\hline BRS Fepagro 24 & $75 \mathrm{bc} \mathrm{A}$ & 69 de $\mathrm{A}$ & $54 \mathrm{~d} \mathrm{~B}$ & $79 \mathrm{ab} A$ & $60 \mathrm{bc} \mathrm{B}$ & $45 \mathrm{~d} \mathrm{C}$ \\
\hline BRS Macota & 91 a $A$ & 82 abc B & 78 a B & 87 a $\mathrm{A}$ & $66 \mathrm{abc} B$ & 64 a B \\
\hline BRS Taura RR & $73 \mathrm{c} \mathrm{A}$ & 62 e B & $67 \mathrm{bc} \mathrm{AB}$ & $68 \mathrm{~b} \mathrm{~A}$ & $54 \mathrm{~cd} \mathrm{~B}$ & $59 \mathrm{ab} \mathrm{AB}$ \\
\hline CD 213 RR & 89 a A & 74 bcd B & $66 \mathrm{bc} \mathrm{C}$ & 87 a A & $63 \mathrm{abc} B$ & $59 \mathrm{ab} B$ \\
\hline CD 221 & 88 a A & $52 \mathrm{fC}$ & $66 \mathrm{bc} B$ & $81 \mathrm{ab} A$ & $44 \mathrm{~dB}$ & $46 \mathrm{~cd} \mathrm{~B}$ \\
\hline Fundacep 53 RR & 92 a A & $84 \mathrm{ab} \mathrm{AB}$ & 83 a B & 92 a A & $69 \mathrm{ab} B$ & 72 a B \\
\hline IAS 5 & $86 \mathrm{ab} A$ & $51 \mathrm{fB}$ & $57 \mathrm{~cd} \mathrm{~B}$ & $81 \mathrm{ab} A$ & $46 \mathrm{~d} \mathrm{~B}$ & 50 bcd B \\
\hline Média & 85 & 71 & 69 & 83 & 61 & 58 \\
\hline $\mathrm{F}$ & \multicolumn{3}{|c|}{$*$} & \multicolumn{3}{|c|}{$*$} \\
\hline CV. $(\%)$ & \multicolumn{3}{|c|}{2,7} & \multicolumn{3}{|c|}{4,7} \\
\hline
\end{tabular}

+ Médias seguidas por mesma letra minúscula na coluna e maiúscula na linha não diferiram pelo teste de Tukey a $5 \%$ de probabilidade; * teste $\mathrm{F}$ significativo a 5\% para a interação genótipo $\mathrm{x}$ tratamento de alagamento; $\mathrm{ns}$ - teste $\mathrm{F}$ não significativo. 
O genótipo BRS 246 RR no primeiro ano não apresentou diferença na germinação, porém obteve no peso de 1000 sementes, assim como a BMX Apollo no segundo ano menor germinação com alagamento no período reprodutivo e maior peso de 1000 sementes.

A distribuição de sementes em peneiras classificadoras apresentou maior retenção nos manejos com alagamento, nas peneiras de maior diâmetro $(6,5$ e 7,5 $\mathrm{mm}) \mathrm{e}$ na peneira $5,5 \mathrm{~mm}$ no manejo sem alagamento. Relacionando o peso de 1000 sementes (Tabela 1) com a distribuição em peneiras classificadoras (Tabelas 3 e 4 ) pode-se observar relação entre o peso e a distribuição das sementes em peneiras.

Como exemplo o genótipo BRS 244 $\mathrm{RR}$ que na primeira safra alcançou maior peso de 1000 sementes com alagamento no estádio reprodutivo, seguido por alagamento no vegetativo e menor valor no tratamento sem alagamento. Neste genótipo observou-se retenção superior na peneira $7,5 \mathrm{~mm}$ no tratamento alagamento no reprodutivo, o que explica o peso de 1000 sementes maior nesta condição. $\mathrm{O}$ valor intermediário para alagamento no período vegetativo pode ser relacionado com maior retenção na peneira
6,5 $\mathrm{mm}$ neste tratamento, já o menor peso observado no tratamento sem alagamento pode ser explicado pela maior retenção na peneira $5,5 \mathrm{~mm}$ neste tratamento.

Na segunda safra novamente o menor peso foi observado no tratamento sem alagamento, resultado que também tem relação com a distribuição de sementes nas peneiras, pois neste tratamento foi constatada maior retenção na peneira 5,5 mm e menor na $6,5 \mathrm{~mm}$ em comparação aos tratamentos com alagamento (Tabela 4).

A peneira $4,5 \mathrm{~mm}$ foi a que apresentou, de maneira geral, menor retenção de sementes não diferindo entre os tratamentos alagamento em todos os genótipos, em ambos os anos de avaliação (Tabelas 3 e 4). Resultado seguido pela peneira $7,5 \mathrm{~mm}$ que também teve uma retenção mais baixa, porém nesta peneira há uma tendência de maior retenção quando ocorre alagamento no período reprodutivo. Na peneira $5,5 \mathrm{~mm}$ há uma retenção considerável no entanto a peneira $6,5 \mathrm{~mm}$ é a que apresenta maior retenção para a maioria dos genótipos. Com exceção do genótipo CD 213 RR na segunda safra, a qual apresentou maior retenção na peneira $5,5 \mathrm{~mm}$. 
Tabela 3. Retenção de sementes de soja em peneiras classificadoras (\%), submetida a três manejos de alagamento do solo: sem alagamento (SA), alagamento período vegetativo (AV) e período reprodutivo (AR), safra 2008/09 (Ano 1). Embrapa Clima Temperado, Capão do Leão-RS, Brasil, 2013.

\begin{tabular}{|c|c|c|c|c|c|c|c|c|c|c|c|c|c|}
\hline \multicolumn{14}{|c|}{ Ano 1 (\% Retenção de sementes) } \\
\hline \multicolumn{7}{|c|}{ BRS 243 RR } & \multicolumn{7}{|c|}{ BRS 244 RR } \\
\hline Peneira & \multicolumn{2}{|l|}{$\overline{\mathrm{AS}}$} & \multicolumn{2}{|c|}{ AV } & \multicolumn{2}{|c|}{ AR } & Peneira & \multicolumn{2}{|c|}{ AS } & \multicolumn{2}{|c|}{$\mathrm{AV}$} & \multicolumn{2}{|c|}{$\mathrm{AR}$} \\
\hline 4,5 & 0,54 & $\mathrm{c} \mathrm{A}$ & 0,43 & c A & 1,96 & c A & 4,5 & 0,41 & $\mathrm{c} \mathrm{A}$ & 0,41 & c A & 0,24 & $\mathrm{~d} A$ \\
\hline 5,5 & 31,24 & b B & 31,13 & $\mathrm{~b} B$ & 42,08 & b A & 5,5 & 19,27 & $\mathrm{~b} A$ & 11,42 & b B & 10,96 & c B \\
\hline 6,5 & 66,57 & a A & 66,91 & a A & 53,06 & a B & 6,5 & 77,65 & a B & 83,68 & a A & 65,1 & a $\mathrm{C}$ \\
\hline 7,5 & 1,65 & c A & 1,53 & c A & 2,91 & c A & 7,5 & 0,78 & $\mathrm{~b} C$ & 4,76 & c B & 23,7 & b A \\
\hline \multicolumn{7}{|c|}{ BRS 246 RR } & \multicolumn{7}{|c|}{ BRS Cambona } \\
\hline Peneira & \multicolumn{2}{|c|}{ AS } & AV & & $\mathrm{AR}$ & & Peneira & \multicolumn{2}{|c|}{ AS } & \multicolumn{2}{|c|}{ AV } & \multicolumn{2}{|c|}{$\mathrm{AR}$} \\
\hline 4,5 & 0,22 & $\mathrm{c} \mathrm{A}$ & 0,15 & c A & 0,33 & $\mathrm{dA}$ & 4,5 & 0,2 & $\mathrm{c} \mathrm{A}$ & 0,17 & c A & 0,22 & c A \\
\hline 5,5 & 21,36 & $\mathrm{~b} A B$ & 23,73 & b A & 17,25 & b B & 5,5 & 16,75 & b B & 22,06 & b A & 17,84 & $\mathrm{c} A B$ \\
\hline 6,5 & 77,65 & a A & 75,41 & a A & 73,97 & a A & 6,5 & 79,69 & a A & 75,69 & a B & 65,86 & a $\mathrm{C}$ \\
\hline 7,5 & 0,78 & $\mathrm{c} \mathrm{B}$ & 0,72 & $\mathrm{c} B$ & 8,33 & $\mathrm{c} \mathrm{A}$ & 7,5 & 3,36 & $\mathrm{c} \mathrm{B}$ & 2,2 & $\mathrm{c} \mathrm{B}$ & 16,08 & b A \\
\hline \multicolumn{7}{|c|}{ BRS Fepagro 24} & \multicolumn{7}{|c|}{ BRS Taura RR } \\
\hline Peneira & \multicolumn{2}{|c|}{ AS } & $\mathrm{AV}$ & \multicolumn{3}{|c|}{$\mathrm{AR}$} & Peneira & \multicolumn{2}{|c|}{ AS } & \multicolumn{2}{|c|}{$\mathrm{AV}$} & \multicolumn{2}{|c|}{ AR } \\
\hline 4,5 & 0,06 & c A & 0,14 & c A & 0,47 & $\mathrm{dA}$ & 4,5 & 0,19 & $\mathrm{c} \mathrm{A}$ & 0,12 & c A & 0,23 & c A \\
\hline 5,5 & 9,15 & b B & 18,73 & b A & 13,7 & $\mathrm{c} A B$ & 5,5 & 5,47 & $\mathrm{cA}$ & 8,19 & b A & 6,1 & c A \\
\hline 6,5 & 87,37 & a A & 78,5 & a B & 64,68 & a $\mathrm{C}$ & 6,5 & 68,65 & a B & 77,32 & a A & 43,19 & $\mathrm{bC}$ \\
\hline 7,5 & 3,43 & bc B & 2,64 & c B & 21,14 & b A & 7,5 & 25,69 & b B & 14,69 & b C & 50,44 & a A \\
\hline \multicolumn{7}{|c|}{ CD 213 RR } & \multicolumn{7}{|c|}{ CD 221} \\
\hline Peneira & \multicolumn{2}{|c|}{ AS } & $\mathrm{AV}$ & & $\mathrm{AR}$ & & Peneira & $\overline{\mathrm{AS}}$ & & $\overline{\mathrm{A}}$ & & $\overline{\mathrm{A}}$ & \\
\hline 4,5 & 0,69 & $\mathrm{c} \mathrm{A}$ & 0,87 & $\mathrm{cA}$ & 1,6 & $\mathrm{c} \mathrm{A}$ & 4,5 & 0,14 & $\mathrm{~d} \mathrm{~A}$ & 0,1 & $\mathrm{c} \mathrm{A}$ & 0,92 & $\mathrm{~d} \mathrm{~A}$ \\
\hline 5,5 & 30,95 & $\mathrm{~b} A B$ & 28,36 & b B & 35,77 & b A & 5,5 & 7,18 & $\mathrm{c} \mathrm{B}$ & 9,71 & b B & 19,38 & b A \\
\hline 6,5 & 67,5 & a A & 63,88 & a $\mathrm{AB}$ & 61,41 & a B & 6,5 & 73,8 & a B & 83,41 & a A & 70,9 & a B \\
\hline 7,5 & 0,85 & c B & 6,88 & c A & 1,21 & $\mathrm{c} \mathrm{B}$ & 7,5 & 18,87 & $\mathrm{~b} A$ & 6,79 & b B & 8,79 & c B \\
\hline & & $\mathrm{CL}$ & S 9911 & & & & & & & IAS 5 & & & \\
\hline Peneira & & & $\mathrm{AV}$ & & $\mathrm{AR}$ & & Peneira & $\overline{\mathrm{AS}}$ & & $\overline{\mathrm{A}}$ & & $\overline{\mathrm{A}}$ & \\
\hline 4,5 & 0,24 & $\mathrm{cA}$ & 0,2 & c A & 0,5 & $\mathrm{dA}$ & 4,5 & 0,08 & $\mathrm{c} \mathrm{A}$ & 0,22 & $\mathrm{c} \mathrm{A}$ & 0,47 & $\mathrm{dA}$ \\
\hline 5,5 & 19,95 & b A & 15,95 & b A & 19,18 & b A & 5,5 & 3,62 & $\mathrm{c} \mathrm{B}$ & 6,19 & $\mathrm{c} A \mathrm{~B}$ & 10,1 & c A \\
\hline 6,5 & 77,4 & a $\mathrm{AB}$ & 81,37 & a A & 72,97 & a B & 6,5 & 51,95 & a $C$ & 69,91 & a A & 60,64 & a B \\
\hline 7,5 & 2,4 & c A & 2,48 & c A & 7,34 & $\mathrm{c} \mathrm{A}$ & 7,5 & 44,35 & b A & 23,67 & b B & 28,8 & b B \\
\hline C.V \% & & & & & & & 14,94 & & & & & & \\
\hline
\end{tabular}

*Médias seguidas por mesma letra minúscula comparam peneiras dentro do mesmo manejo de alagamento e maiúscula comparam manejos de alagamento dentro de um mesmo diâmetro de peneiras, pelo teste de Tukey a 5\% de probabilidade. 
Tabela 4. Retenção de sementes de soja em peneiras classificadoras (\%), submetida a três manejos de alagamento do solo: sem alagamento (SA), alagamento período vegetativo (AV) e período reprodutivo (AR), safra 2009/10 (Ano 2). Embrapa Clima Temperado, Capão do Leão, RS, Brasil, 2013.

\begin{tabular}{|c|c|c|c|c|c|c|c|c|c|c|c|c|c|}
\hline \multicolumn{14}{|c|}{ Ano 2 (\% Retenção de sementes) } \\
\hline \multicolumn{7}{|c|}{ Apolo } & \multicolumn{7}{|c|}{ BRS 244 RR } \\
\hline Peneira & \multicolumn{2}{|c|}{ AS } & \multicolumn{2}{|c|}{$\mathrm{AV}$} & \multicolumn{2}{|l|}{$\mathrm{AR}$} & \multirow{2}{*}{$\begin{array}{c}\text { Peneira } \\
4,5\end{array}$} & \multicolumn{2}{|c|}{$\mathrm{AS}$} & \multicolumn{2}{|c|}{ AV } & \multicolumn{2}{|c|}{$\mathrm{AR}$} \\
\hline 4,5 & 4,88 & $\mathrm{c} \mathrm{A}$ & 3,1 & $\mathrm{c} \mathrm{A}$ & 1,12 & $\mathrm{c} \mathrm{A}$ & & 4,24 & $\mathrm{~b} \mathrm{~A}$ & 0,48 & $\mathrm{c} \mathrm{A}$ & 2,83 & $\mathrm{c} \mathrm{A}$ \\
\hline 5,5 & 61,49 & a A & 56,03 & a A & 32,08 & b B & 5,5 & 44,51 & a A & 23,19 & b B & 22,4 & b B \\
\hline 6,5 & 33,47 & $\mathrm{~b} C$ & 40,01 & b B & 65,49 & a A & 6,5 & 50,4 & a B & 73,62 & a A & 72,6 & a A \\
\hline 7,5 & 0,15 & $\mathrm{c} \mathrm{A}$ & 0,49 & $\mathrm{c} \mathrm{A}$ & 1,31 & $\mathrm{c} \mathrm{A}$ & 7,5 & 0,84 & b A & 2,63 & $\mathrm{c} \mathrm{A}$ & 2,13 & $\mathrm{c} \mathrm{A}$ \\
\hline \multicolumn{7}{|c|}{ BRS 246 RR } & \multicolumn{7}{|c|}{ Fundacep 53 RR } \\
\hline Peneira & \multicolumn{2}{|c|}{ AS } & \multicolumn{2}{|c|}{ AV } & \multicolumn{2}{|c|}{$\mathrm{AR}$} & Peneira & \multicolumn{2}{|c|}{ AS } & \multicolumn{2}{|c|}{ AV } & \multicolumn{2}{|c|}{ AR } \\
\hline 4,5 & 6,37 & $\mathrm{c} \mathrm{A}$ & 1,75 & $\mathrm{c} \mathrm{A}$ & 3,37 & $\mathrm{c} \mathrm{A}$ & 4,5 & 2,86 & $\mathrm{c} \mathrm{A}$ & 0,7 & c A & 2,01 & $\mathrm{c} \mathrm{A}$ \\
\hline 5,5 & 76,86 & a A & 58,81 & a B & 61,61 & a B & 5,5 & 62,08 & a A & 31,2 & b C & 41,4 & b B \\
\hline 6,5 & 16,74 & b B & 39,22 & b A & 35,11 & $\mathrm{~b} A$ & 6,5 & 34,87 & $\mathrm{~b} C$ & 67,62 & a A & 55,7 & a B \\
\hline 7,5 & 0,02 & $\mathrm{~d} A$ & 0,21 & $\mathrm{c} \mathrm{A}$ & 0,32 & $\mathrm{cA}$ & 7,5 & 0,18 & $\mathrm{cA}$ & 0,47 & c A & 0,7 & c A \\
\hline \multicolumn{7}{|c|}{ BRS Fepagro 24} & \multicolumn{7}{|c|}{ BRS Taura RR } \\
\hline Peneira & \multicolumn{2}{|c|}{ AS } & \multicolumn{2}{|c|}{$\mathrm{AV}$} & \multicolumn{2}{|c|}{$\mathrm{AR}$} & Peneira & \multicolumn{2}{|c|}{ AS } & \multicolumn{2}{|c|}{$\mathrm{AV}$} & \multicolumn{2}{|c|}{$\mathrm{AR}$} \\
\hline 4,5 & 0,79 & $\mathrm{c} \mathrm{A}$ & 0,5 & $\mathrm{c} \mathrm{A}$ & 0,33 & $\mathrm{c} \mathrm{A}$ & 4,5 & 1,04 & $\mathrm{c} \mathrm{A}$ & 0,48 & c A & 0,37 & c A \\
\hline 5,5 & 28,8 & b A & 27,16 & b A & 15,82 & b B & 5,5 & 30,72 & b A & 12,49 & b B & 11,59 & b B \\
\hline 6,5 & 68,81 & a A & 69,15 & a A & 72,34 & a A & 6,5 & 66,64 & a B & 77,7 & a A & 76,02 & a A \\
\hline 7,5 & 1,58 & $\mathrm{c} \mathrm{B}$ & 3,17 & $\mathrm{c} \mathrm{B}$ & 11,49 & b A & 7,5 & 1,59 & $\mathrm{c} B$ & 9,31 & b A & 12,01 & b A \\
\hline & & & D213 R & & & & & & & D 221 & & & \\
\hline Peneira & $\mathrm{AS}$ & & & & & & Peneira & $\mathrm{A}$ & & $\mathrm{A}$ & & & \\
\hline 4,5 & 7,07 & $\mathrm{c} \mathrm{A}$ & 2,77 & $\mathrm{c} \mathrm{A}$ & 4,68 & $\mathrm{c} \mathrm{A}$ & 4,5 & 2,51 & $\mathrm{c} \mathrm{A}$ & 0,52 & $\mathrm{~d} \mathrm{~A}$ & 0,85 & $\mathrm{c} \mathrm{A}$ \\
\hline 5,5 & 75,34 & a A & 70,02 & a A & 55,8 & a B & 5,5 & 41,1 & b A & 25,91 & b B & 26,39 & b B \\
\hline 6,5 & 17,59 & $\mathrm{~b} C$ & 26,93 & b B & 39,3 & a A & 6,5 & 55,75 & a B & 65,26 & a A & 68,59 & a A \\
\hline 7,5 & 0 & $\mathrm{~d} A$ & 0,26 & $\mathrm{c} \mathrm{A}$ & 0,21 & $\mathrm{c} \mathrm{A}$ & 7,5 & 0,63 & $\mathrm{c} \mathrm{B}$ & 8,3 & c A & 4,16 & c $\mathrm{AB}$ \\
\hline & & & S Maco & & & & & & & IAS 5 & & & \\
\hline Peneira & $\mathrm{AS}$ & & & & & & Peneira & $\mathrm{A}$ & & $\mathrm{A}$ & & & \\
\hline 4,5 & 3,22 & $\mathrm{c} \mathrm{A}$ & 1,66 & $\mathrm{c} \mathrm{A}$ & 2,44 & $\mathrm{c} \mathrm{A}$ & 4,5 & 1,67 & $\mathrm{c} \mathrm{A}$ & 0,37 & $\mathrm{~d} \mathrm{~A}$ & 1,7 & $\mathrm{c} \mathrm{A}$ \\
\hline 5,5 & 74,81 & a A & 66,98 & a B & 53,74 & a $C$ & 5,5 & 41,72 & b A & 14,85 & b B & 29,72 & b B \\
\hline 6,5 & 21,84 & $\mathrm{~b} C$ & 31,09 & b B & 43,23 & b A & 6,5 & 56,21 & a C & 76,82 & a A & 63,62 & a B \\
\hline 7,5 & 0,11 & $\mathrm{c} \mathrm{A}$ & 0,26 & $\mathrm{c} \mathrm{A}$ & 0,58 & $\mathrm{cA}$ & 7,5 & 0,39 & $\mathrm{c} B$ & 7,95 & c A & 4,95 & $\mathrm{c} A B$ \\
\hline C.V \% & & & & & & & 11,75 & & & & & & \\
\hline
\end{tabular}

*Médias seguidas por mesma letra minúscula comparam peneiras dentro do mesmo manejo de alagamento e maiúscula comparam manejos de alagamento dentro de um mesmo diâmetro de peneiras, pelo teste de Tukey a 5\% de probabilidade. 


\section{CONCLUSÕES}

A qualidade fisiológica de sementes é afetada negativamente pelo alagamento do solo, impedindo a produção de sementes com qualidade. Nas regiões de várzea há produção de sementes de qualidade quando não há alagamento do solo. $\mathrm{O}$ alagamento altera a distribuição das sementes em peneiras classificadoras, e com o alagamento há tendência de maior retenção em peneiras de maior diâmetro. Há relação entre o peso de 1.000 sementes e a distribuição das sementes em peneiras.

\section{AGRADECIMENTOS}

Ao Fundo de Pesquisa da Embrapa/Monsanto pelo auxílio na realização deste trabalho.

\section{REFERÊNCIAS BIBLIOGRÁFICAS}

AMARANTE, L.; COLARES, D. S.; OLIVEIRA， M. L.; ZENZEN, I. L.; BADINELLI, P. G.; BERNARDI, E. 2007. Teores de clorofilas em soja associada simbioticamente com diferentes estirpes de Bradyrhizobium sob alagamento. Revista Brasileira de Biociências, Porto Alegre, v. 5, n.2, p. 906-908.

BRASIL. 2009. Ministério da Agricultura, Pecuária e Abastecimento. Regras para análise de sementes. Brasília: MAPA/ACS, 399p.

BUCKERIDGE, M. S.; SANTOS, H. P.; TINÉ, M. A. S. 2000. Mobilisation of storage cell wall polysaccharides in seeds. Plant Physiology and Biochemistry, New Delhi, 38, p. 141156.

CASAGRANDE, E. C.; FARIAS, J. R. B.; NEUMAIER, N.; PEDROSO, J.; MARTINS, P. K.; BRETON, M. C.; NEPOMUCENO, A. L. 2001. Expressão gênica diferencial durante déficit hídrico em soja. Revista Brasileira de Fisiologia Vegetal, Campinas, v. 13, n. 2, p. 168-184.

CHO, J.; YAMAKAWA, T. 2006. Effects on growth and seed yield of small seed soybean cultivars of flooding conditions in paddy field. Journal of the Faculty of Agriculture, Fukuoka,v. 51, n. 2, p. 189-193.

DREW, M. C.; HE, C. J.; MORGAN, P. W. 2000. Programmed cell death and aerenchyma formation in roots. Trends in Plant Science, Londres, v. 5, n. 3, p. 123-127.

FEHR, W.; CAVINESS, R. H. 1977. Stages of soybean development. Special Report 80. Iowa State University Ames, Iowa. $11 \mathrm{pp}$.

FRANÇA-NETO, J. B.; KRZYZANOWSKI, F. C.; HENNING, A. A.; COSTA, N. P. 2000. Tecnologia de produção de sementes. In: Embrapa Soja. A cultura da soja no Brasil. Londrina. $262 \mathrm{pp}$.

HAJDUCH, M.; GANAPATHY, A.; STEIN, J. W.; THELEN, J.J. A. 2005. Systematic proteomic study of seed filling in soybean. establishment of highresolution two-dimensional reference maps, expression profiles, and an interactive proteome database. Plant Physiology, Waterbury, 137, p. 13971419.

KLOK, E. J.; WILSON, I.W.; WILSON, D.; CHAPMAN, S. C.; EWING, R.M.; SOMERVILLE, S. C.; PEACOCK, W. 
J.; DOLFERUS, R.; DENNIS, E. S. 2002. Expression profile analysis of the low-oxygen response in Arabidopsis root cultures. The Plant Cell, Waterbury, 14, p. 2481-2494.

KUSS, R. C. R.; KÖNIGII, O.; DUTRA, L. M. C.; BELlÉ, R. A.; ROGGIAI, S.; STURMER, G. R. 2008. Populações de plantas e estratégias de manejo de irrigação na cultura da soja. Ciência Rural, Santa Maria. v. 38, n. 4, p. 11331137.

LORETI, E.; POGGI, A.; NOVI, G.; ALPI, A.; PERATA, P. 2005.A Genome-wide analysis of the effects of sucrose on gene expression in Arabidopsis seedlings under anoxia. Plant Physiology, Waterbury, 137, p. 1130-1138.

MAGALHÃES, P. C.; COELHO, C. H. M.; GAMA, E. E. G.; GUIMARÃES, P. E. O.; GUIMARÃES, C. T.; DURÃES, F. O. M.; BORÉM. A. 2005. Avaliação dos ciclos de seleção da variedade BRS 4154 - Saracura para tolerância ao encharcamento do solo. Embrapa Milho e Sorgo. Circular Técnica, Sete Lagoas, v. 67, p. 4.

MARCOS FILHO, J.; NOVEMBRE, A. D. C.; CHAMMA, H. M. C. P. 2000. Tamanho da semente e o teste de envelhecimento acelerado para soja. Scientia Agricola, Piracicaba, v. 57, n. 3, p. 473-482.

MARCOS FILHO, J. 2005. Fisiologia de sementes de plantas cultivadas. Piracicaba: FEALQ, 495 p.

RAMBO, L.; COSTA, J. A.; PIRES, J. L. F.; PARCINELLO, G.; FERREIRA, F. G. 2003. Rendimento de grãos da soja em função do arranjo de plantas. Ciência Rural, Santa Maria, v. 33, n. 3, p. 405411.

SERRES, B. J.; VOESENEK, L. A. C. J. 2008. Flooding Stress: Acclimations and Genetic Diversity. Annual Review of
Plant Biology, Palo-Alto, vol. 59, p. 313-39.

SUlLIVAN, M; VANTOAI, T. T.; FAUSEY, N.; BEUERLEIN, J.; PARKISON, R.; SOBOYEJO, A. 2001. Evaluating On-Farm Flooding Impacts on Soybean. Crop Science, Madison. 41: p. 93-100.

ZENZEN, I. L.; AMARANTE, L; COLARES, D. S.; OLIVEIRA, M. L.; BERNARDI, E.; COSTA, E. L. G.; NASCIMENTO, J. S. 2007. Área Foliar e Volume do Sistema Radicular em Plantas de Soja Inoculadas com Estirpes de Bradyrhizobium e Submetidas ao Alagamento. Revista Brasileira de Biociências, Porto Alegre, v. 5, n. 2, p. 1092-1094.

Recebido em: $27 \backslash 02 \backslash 2014$ Aceito para publicação em: $02 \backslash 05 \backslash 2015$ 